\title{
A preliminary study on the cause of conflicts in multidis- ciplinary collaboration
}

\author{
Shou-Te Pan ${ }^{1}$, Li-Shu Lu ${ }^{2 *}$ \\ 1,2 Digital Media Design, Yunlin, Taiwan
}

\section{Keywords \\ Multidisciplinary \\ Team collaboration \\ Team communication \\ Cause of conflicts}

Received: 07 December 2019

Accepted: 03 January 2019

Published: 20 February 2019

\begin{abstract}
The current research explored the causes of conflicts in multidisciplinary team collaboration. This study proposed to take multidisciplinary teamwork conflicts as the subject to summarize the conflicts in this field by analyzing and summarizing the content of many cases. In the study, relevant research on multidisciplinary teams was collected over the ten years and selected five papers involving the research on the cooperation process of the same. We found that each team involved at least three fields, namely engineering, management, and management design. This paper sorted out the problems arising from multidisciplinary collaboration through content analysis. It grouped them through the KJ method (also called affinity diagram method), collaborating with researchers with exact experience for further analysis and induction. According to the study, problems encountered by multidisciplinary teams can be classified into nine categories: professional background, team composition, task allocation, role positioning, relationship, communication, attitude, efficiency, and external factors. To be specifically This study is expected to clarify the problems arising in the process of multidisciplinary team collaboration, providing references for subsequent researchers.
\end{abstract}

(c) 2019 The Author(s). Published by TAF Publishing.

\section{INTRODUCTION}

\section{Research Background and Purpose}

In recent years, five major trends including "globalization", "lower birthrate", "aging", "digitalization" and "global warming" are seen around the world. It's influence and impact on global education is particularly significant and obvious. The education environment in Taiwan is faced with three backgrounds: "university supply exceeds demand", "labor supply and demand are imbalanced" and "12-year national education is about to be implemented". Under such trends and backgrounds, the Ministry of Education released Ministry of Education's White Paper of Personal Training in 2013 to plan a blueprint for personnel cultivation in the next 10 years. It is expected to have our talented persons be with "global mobility", "job competence", "innovation strength", "cross-domain capability", "information informed", "global citizenship" and other critical abilities (Ministry of Education, 2013).

Among them, "multidisciplinary capability" refers to a fact that under world-wide competition, running a business is no longer a work to be completed by individuals all alone, but requires team efforts among marketing, manufacturing, designing and other departments (Y.-C. Lin, 2010). Data scientist, story manager, solution architect, community manager, and other new careers are springing up, which all require to integrate different professional knowledge (Hou, 2007). As shown from all signs, the multidisciplinary capability is gradually becoming an essential quality, and the concept of T-type talents is born from this.

The concept of T-type talents was proposed by Dorothy Barton, professor of Harvard Business School. Simply put, it is not enough to have one specialty; a second and third specialty is a must in such an era of drastic changes (Zhao, 2014). It means that a talented guy should have expertise in an individual field with crosswise knowledge and/or macro understanding; or have a deep expertise in something with broad lateral knowhow (Li, 2017; H. Liu \& Dong, 2016; Nissa, Jhatial, Nawaz, \& Halepota, 2018).

\footnotetext{
${ }^{*}$ corresponding author: Li-Shu Lu
}

†email: lazywolfmax@gmail.com 
In response to the significant changes in industrial environment and talent demand, education is expected to make a shift from single-background single-field education to cross-field education, to meet practical needs. In this context, a number of colleges and institutions have tried to cross such threshold by setting up inter-disciplinary programs, including degree programs and credit programs, all is derived from the cooperative development needs in academic sectors, and the high demand for cross-field talents (P.-L. Liu et al., 2006). Unfortunately, due to poor foundation and experience, many courses are reduced to experiments and fail to provide students with a good guidance. In the meanwhile, most researches on domestic cross-field team collaboration are focused on causal relationship, that is, they usually designed some controlling independent variables and observed their impact on targeted variables in a certain way, but seldom cared about the team itself and the problems arising from the process of team collaboration. Therefore, the author is working to explore a deep insight in the said process and find the cause of the problems through reference to many multidisciplinary research cases, hoping to reduce the occurrence of such problems in multidisciplinary team collaboration, eliminate the chance of team conflicts and provide reference for subsequent researchers.

\section{Research Purpose}

Based on the above research background and motivation, many universities and colleges have set up a number of inter-disciplinary courses and programs in response to the call of the times and the demand of industrial talents. Well, the result is not as good as expected. Besides, there are few studies focusing on the team and its collaboration process. That's why this study proposed to take multidisciplinary teamwork conflicts as the subject, to summarize the conflicts in this filed by analyzing and summarizing the content of many cases. The specific research purposes are as follows:

(1) to collect relevant research cases of cross-field collaboration and analyze the problems arising wherefrom accordingly.

(2) to summarize and classify the problems arising in the process on multidisciplinary collaboration and analyze them by classification.

\section{DISCUSSION ON LITERATURE RELATED TO MULTIDIS- CIPLINARY COLLABORATION CONFLICTS}

The concept "team" was developed from theory of organization. Shonk (1982) defined team as a group of two or more members who work to accomplish common tasks through mutual dependence and coordination to achieve their goals. Based on this theory, subsequent researchers put forward multiple definitions of "team". Guzzo, Yost, Campbell, and Shea (1993) emphasized that common goals can be achieved independently; Shaw, Duffy, and Stark (2000) emphasized to reach a common goal under a common management. Besides, a team can be classified into cross-department team, cross-functional team, multinational team, project team and virtual team of different forms of composition and organization according to its objectives and the needs and characteristics of its members (Lan, 2012; Raditya, 2018). As for cross-disciplinary team, Brown and Eisenhardt (1995) defined it as an organizational structure consisting of two or more people in different fields. Robbins (1996) suggested that cross-disciplinary teams can integrate multiple skills, knowledge, and experience to maximize the team's overall ability beyond the capabilities of individuals.

However, for a team, individual differences among team members may lead to conflicts. Kunhui and Derui (2000) defined conflict as an interactive process of contradiction and opposition between individuals, groups or organizations due to different goals, cognition, emotions and/or behaviors. That is, conflict is not a matter of instant occurrence, but an interactive process, a process of problem generation. In an interdisciplinary team, members are from different areas of expertise, offering a variety of expertise, perspectives, and experiences (Denton, 1997). While different domains may have different goals and values (Parry \& Song, 1993). Therefore, interdisciplinary team is more likely to bring about conflicts, compared with traditional singledomain teams, and may lead to organizational conflicts as the relationship between professional functions becomes complicated for such an organization has violated traditional single-leader management principle (Wheelwright \& Clark, 1992).

In the traditional study of organizational conflict in management, conflicts have been classified by many scholars in various ways. According to the chronological order, they are as follows: Guetzkow and Gyr (1954) proposed substantive conflict and emotional conflict. Substantive conflict is talking about team tasks, which refers to the fact that team members have inconsistent opinions on how to complete the tasks; while Coser (1998) defined goal orientation conflict as a situation where team members have different opinions on the goal of the task, while emotional conflict refers to negative emotional reactions of team members, such as anger and jealousy. Pondy (1967) divided the conflicts existing in an organizational structure into negoti- 
ation conflicts, bureaucratic conflicts and system conflicts, where negotiation conflict is caused by interests of different groups rising from allocation of team resources; bureaucratic conflicts at lower levels is caused by organizational structure, for example, decision-making bias due to unequal power delegation among team members; system conflict is job related caused by the friction generated among the team members in their working process. The most preventative classification is the three categories of conflicts proposed by Jehn (1997), which have been taken as the basis by lots of subsequent researchers. It consisted of task conflict, relationship conflict and process conflict, of which, task conflict involves conflicts resulting from differences of opinions in relation to the content of the tasks performed; relationship conflict refers to the incompatibility of team members in interpersonal relationships; while process conflict can be defined as conflicts about how task accomplishment should be proceeded in the work unit, who is responsible for what, and how things should be delegated.

Based on the above, it can be found that the occurrence of team conflicts is closely related to the problems arising from the team collaboration process. Cross and Cross (1995) argued that conflict is inevitable in a team for it may come about from different interpretations, different cognitions, different concepts and different propositions and any different things like this (Y.-C. Lin, 2010).

\section{A CASE STUDY ON MULTIDISCIPLINARY COLLABORA- TION}

\section{Case Collection}

The study contains a collection of multidisciplinary collaboration research findings in the form of journals and treatises. It has been found that a typical Chinese multidisciplinary team consists primarily of engineering, design, management and medical personnel. A multidisciplinary medical team consists primarily of physicians and paramedics representing different medical fields and technologies and involves no virtual expansion into nonmedical fields. Therefore, the study performed a preliminary screening of the journals and treatises dealing with multidisciplinary medical teams to prepare the following Table 1:

TABLE 1. Case collection

\begin{tabular}{|c|c|}
\hline Research Name & Reference \\
\hline $\begin{array}{l}\text { An empirical study of how academic motivation and social ability influence on learning outcome in cross-disciplinary collaborative } \\
\text { learning }\end{array}$ & (Ou, 2009) \\
\hline Exploring the Process of Interdisciplinary Communication - A Case Study of Design and Marketing Interdisciplinary Team & (Yeh, 2009) \\
\hline Exploring Multidisciplinary Teamwork Design Process for Cross-Disciplinary Learning & $(\mathrm{Ke}, 2008)$ \\
\hline The Concept Thinking Context of Interdisciplinary Design Team - A Case Study of joining Members in Sociology Department & (Huang, 2009) \\
\hline $\begin{array}{l}\text { Exploring the Influence of Scenario Approach on Multidisciplinary Collaboration Design-An Case Study of USER-ORIENTED Innovative } \\
\text { Design Course }\end{array}$ & (Y.-C. Lin, 2010) \\
\hline The Influence and Problems of Scenario Design Approach on Multi-disciplinary Collaboration Design & (Tang \& Lin, 2011) \\
\hline $\begin{array}{l}\text { A Study of the Relationships between Leader Personality, Team Learning, and Team Performance - Evidence from Cross-Functional } \\
\text { Design Courses }\end{array}$ & (Lai, 2010) \\
\hline The Research of Applying Electronic Learning Portfolio in Cross-disciplinary Collaborative Learning & (C.-H. Wu, 2010) \\
\hline $\begin{array}{l}\text { Exploring the Integrating Process of the Cross-Field Open Innovation Team : A Case Study of Promoting Program for Cross-Field Creative } \\
\text { Scenario Value-Adding of National Science Council }\end{array}$ & (Lan, 2012) \\
\hline $\begin{array}{l}\text { The Case Study of Establishing Interdisciplinary R\&D Team By Academy Cooperation Between A University and Romp Enterprise Co.; } \\
\text { Ltd. }\end{array}$ & (C.-Y. Lin, 2011) \\
\hline The Cross-disciplinary Team Design Model of Cultural Products & (Lay, 2012) \\
\hline Competition Learning through Cross-Disciplinary Collaboration in the Entrepreneur Competitions & (Chen, 2012) \\
\hline The Study Of Using Animation To Convey The Business Model And Guiding The Multidisciplinary Design Team Innovation Activities & (Tsao, 2014) \\
\hline Team Learning in Open Innovation Teams: The Case of the MOST Promoting Program for Cross-Field Creative Scenario Value-Adding & (K.-Y. Wu, 2017) \\
\hline A Study of Integrating Mechanism for the Cross-Field Team between Performing Arts and Technology & (Shih, 2017) \\
\hline
\end{tabular}


As shown above, when it comes to multidisciplinary collaboration, most domestic studies center on exogenous factors rather than addressing the conflicts in team collaboration per se and the related problems. Therefore, the study further sifted through the above documentation to identify and select multidisciplinary team collaboration cases for the purpose of the investigation (see the following Table 2) of five individual cases.

TABLE 2. The result of case screening

\begin{tabular}{|c|c|c|}
\hline Number & Research Name & Reference \\
\hline Case 1 & $\begin{array}{l}\text { Exploring the Process of Interdisciplinary Communication-A Case Study of Design and Marketing } \\
\text { Interdisciplinary Team }\end{array}$ & (Yeh, 2009) \\
\hline Case 2 & $\begin{array}{l}\text { Exploring the Influence of Scenario Approach on Multidisciplinary Collaboration Design - An Case } \\
\text { Study of USER-ORIENTED Innovative Design Course }\end{array}$ & (Y.-C. Lin, 2010) \\
\hline Case 3 & $\begin{array}{l}\text { The Influence and Problems of Scenario Design Approach on Multi-disciplinary Collaboration De- } \\
\text { sign }\end{array}$ & (Tang \& Lin, 2011) \\
\hline Case 4 & $\begin{array}{l}\text { Exploring the Integrating Process of the Cross-Field Open Innovation Team : A Case Study of Pro- } \\
\text { moting Program for Cross-Field Creative Scenario Value-Adding of National Science Council }\end{array}$ & (Lan, 2012) \\
\hline Case 5 & Competition Learning through Cross-Disciplinary Collaboration in the Entrepreneur Competitions & (Chen, 2012) \\
\hline
\end{tabular}

\section{KJ Method}

As indicated by a summation of the above cases, although the researchers used different descriptive languages for the various problems, many were observably shared by multidisciplinary teams in collaboration. At the next stage, the KJ method was used to assort and sum up data. It enables data segmentation, unitization, integration, processing and sorting for the purpose of conceptualizing quantitative analysis and making more objective qualitative analysis. Furthermore, the concept of clustering, built on data unitization, relates to grouping attribute-similar content in clusters for analytically summing up the sample characteristics (Ruan \& et al., 2012). The following included a brief introduction to the KJ procedure as a research method.

\section{Card making}

Cards were made based on the above case findings and on condition of separation of the content into sentences of independent minimum significance (Ruan \& et al., 2012). The procedure is as follows Figure 1.

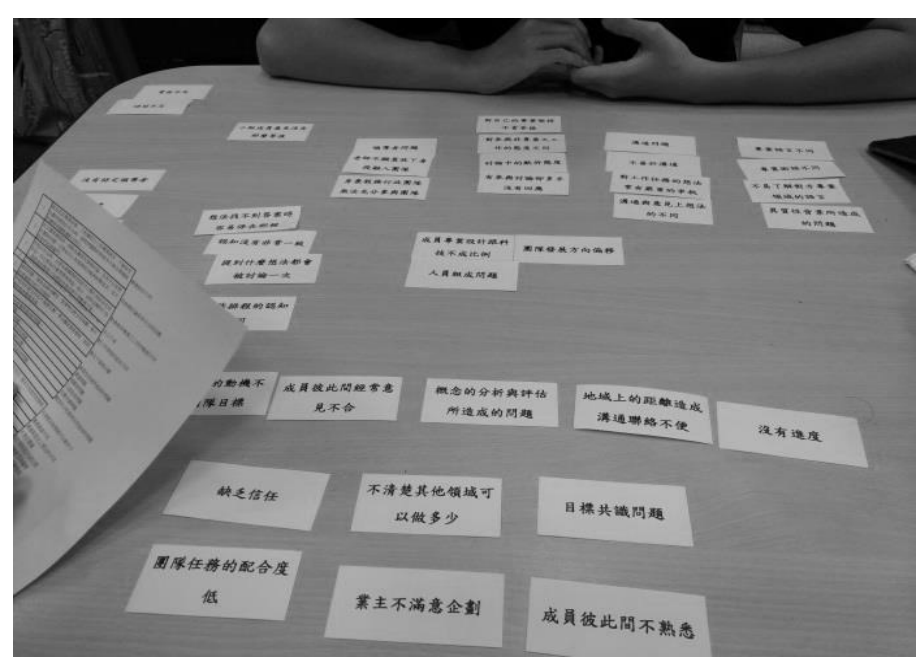

FIGURE 1. KJ method card making

\section{Grouping}

For this KJ method-based study, two fellows with experience of multidisciplinary collaboration were invited to inspect, along with the researcher(s), all cards and sort out those with the same attributes, which were grouped and named. Cards signifying disagreement were discussed for many times and the already assorted cards inspected time and again to derive the final results. The procedure is as follows Figure 2. 


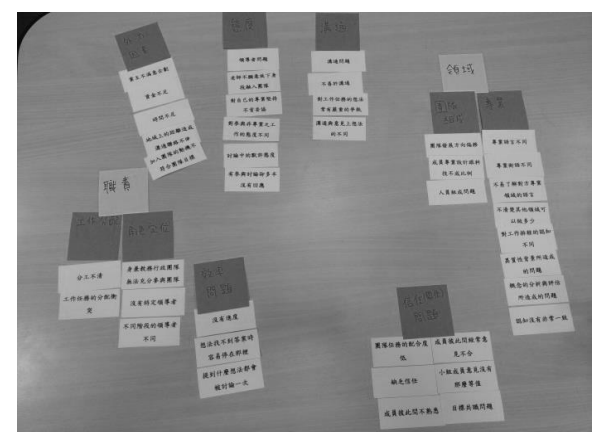

FIGURE 2. KJ method grouping

\section{Case Study}

Case 1: Exploring the process of interdisciplinary communication-A case study of design and marketing interdisciplinary team

Case 1 investigated multidisciplinary team communication with an analysis of the correlation between communication barriers and team performance designed to identify the source and impact of the barriers on team performance. Yeh
(2009) credited multidisciplinary communication barriers primarily to member heterogeneity.

In the analysis Yeh (2009) pointed out the significant divide in cognitive style between the corporate management personnel and the business design personnel. The following Table 3 prepared by Yeh (2009) outlined the existing multidisciplinary team collaboration problems in regard of communication, initial collaboration and collaboration.

TABLE 3. The problem of the case 1

1 The two groups of personnel have different backgrounds and their respective terminological systems. In most cases, the groups cannot mutually explicate the crux of the problem clearly, whether in planning or designing a work.

2 While the business design personnel discuss business plan development, they mostly do not respond to the corporate management personnel, who wish to seek advice from the business design personnel rather than struggle on their own.

3 The corporate management personnel have no practical techniques to offer to and help the business design personnel complete the designs. Despite the desire of the corporate management personnel to get involved, the business design personnel will either show acceptance or reluctance in terms of external intervention.

4 Some groups have role division problems, e.g., ambiguous role division.

5 Progress is also a problem. The business design personnel have a tendency to accept more flexible routines and don't care much about the working schedule.

6 Some clients dissatisfied with the business plans may demand rework done by the team, seriously delaying progress.

\section{Case 2: Exploring the influence of scenario approach on} multidisciplinary collaboration design-A case study of user-oriented innovative design course

The study focused primarily on how the scenario approach works on multidisciplinary collaborative design whose application contributes to the insights into design and study. Y.-C. Lin (2010) conducted an interview and summed up six problems with multidisciplinary collaborative design. see the following Table 4:

TABLE 4. The problem of the case 21

1 Heterogeneity of backgrounds.

2 Communication.

3 Leadership.

4 Team composition.

5 Common goals.

6 Concept analysis and assessment.
Case 3: The influence and problems of scenario design approach on multi-disciplinary collaboration design

The study, focusing primarily on how the scenario approach works on multidisciplinary collaborative design, employed participant observation, questionnaires and interviews to establish how the scenario approach impacts positively on communication, design and the exchange of ideas in regard of multidisciplinary collaborative design programs.

Through the interviews of learners, Tang and Lin (2011) investigated multiple collaboration problems listed as following Table 5: 
TABLE 5. The problem of the case 3

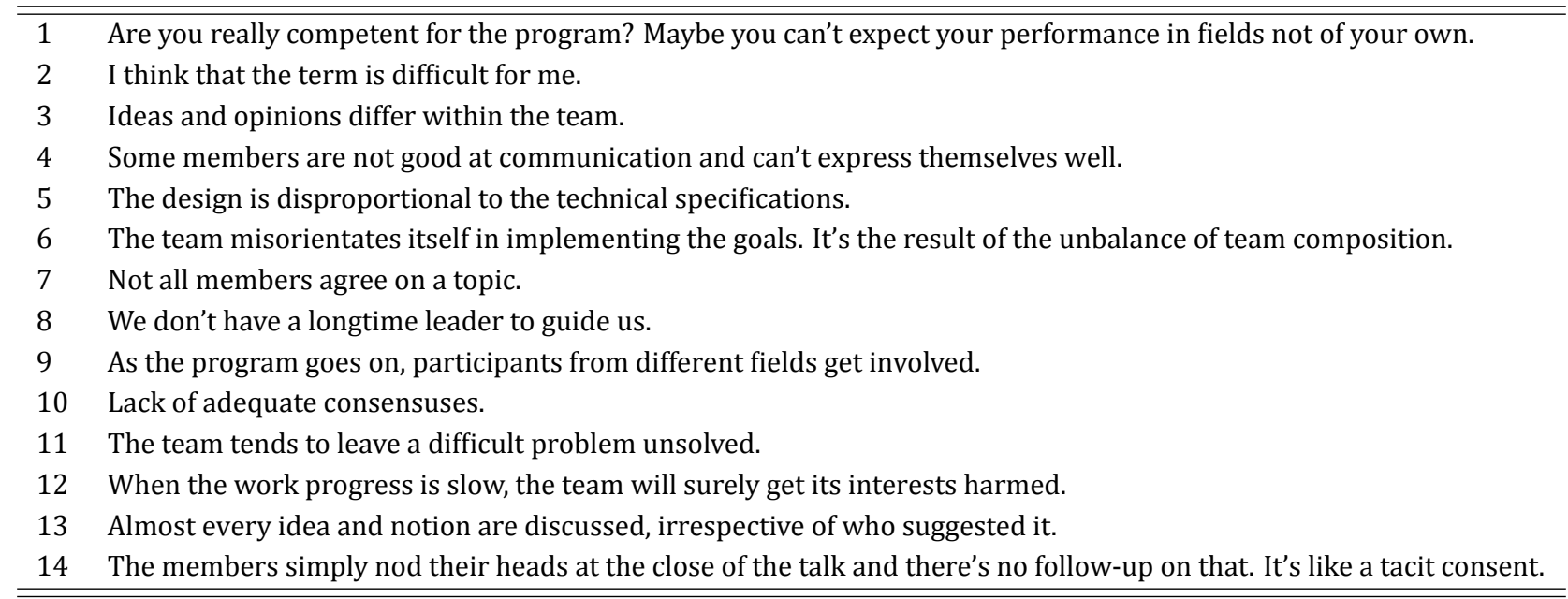

Case 4: Exploring the integrating process of the crossfield open innovation team: A case study of promoting program for cross-field creative scenario value-adding of national science council

The study Lan (2012), discussed primarily the internal consolidation of an open innovation team and the related mech- anism. It was suggested that official and unofficial consolidation mechanisms be introduced to boost the multidisciplinary collaboration within an open innovation team. This case also have multiple collaboration problems listed as following Table 6:

TABLE 6. The problem of the case 4

\begin{tabular}{ll}
\hline \hline 1 & Some members insist on their ideas based on specialty. It results in lack of consensuses. \\
2 & The members can't understand each other with ease because of professional terminology. \\
3 & The motivation of some participants doesn't comply with the team goals. \\
4 & The instructors “deign” to work with other members. \\
5 & The members are not familiar with one another. \\
6 & Geographical distance results in poor connection and communication. \\
7 & Funds and time insufficiency. \\
8 & Some instructional or administrative officials can't spare adequate time for team affairs. \\
9 & Poor coordination in teamwork. \\
10 & Lack of trust. \\
\hline \hline
\end{tabular}

Case 5: Competition learning through cross-disciplinary collaboration in the entrepreneur competitions

The study, conducted by Chen (2012) aimed to explore whether a multidisciplinary team would compromise competitive learning in a creative competition.by quantifying three aspects, i.e., teamwork, interpersonal communication and emotion management, of multidisciplinary collaboration and competitive learning. As shown by the results, the members of the multidisciplinary team are often divided in opinions, therefore coming into (serious) conflicts in regard of tasks and task allocation. listed as following Table 7:

TABLE 7. The problem of the case 5

\begin{aligned} & \hline \hline 1 We're often divided in opinions. \\ & 2 We often have serious conflicts in regard of tasks. \\ & 3 We have conflicts in regard of task allocation. \\ & \hline \hline\end{aligned}

\section{Comprehensive Analysis and Discussion}

The adoption of the KJ method identified nine multidisciplinary team collaboration problems, including specialty, team composition, task allocation, role positioning, relationship, communication, attitude, efficiency and external factors. 
The specialty problem concerned professional language, terminology, jargon, failure to expect performance in unfamiliar fields, lack of consensuses on the working schedule, background heterogeneity, concept analysis and assessment, and lack of consensuses. The team composition problem concerned team composition, designs disproportionate to technical specifications, and team mis-orientation in goal implementation. The task allocation problem concerned unclear role division and tasking conflict. The role positioning problem concerned lack of consistent leadership and insufficient involvement of instructional or administrative officials. The relationship problem concerned unfamiliarity of the members with each other, consensuses \& goals, persisting disagreement among the members, unavailability of agreement on specific topics, poor coordination and lack of trust. The communication problem concerned communication barrier, different opinions, persisting serious conflicts of tasks, and communication ability inadequacy. The attitude problem concerned lack of responses to most discussions, tacit consent in discussions, insistence on ideas based on specialty, participation in programs other than one's own, leadership, and unwillingness of instructors to become part of the team. The efficiency problem concerned discussions of almost all the ideas and notions, tendency to leave difficult problems unsolved, and slow progress. The external factor problem concerned lack of funding, lack of time, communication barrier attributable to geographical distance, dissatisfaction of clients with business plans, and noncompliance of the motivation of some participants with the team goals. The nine problems were discussed separately as follows.

\section{Specialty and Team Composition}

Professional background is universal in any multidisciplinary team that encompasses two or more specialties. Different technical backgrounds result directly in different professional languages, so conflicts may arise out of mutual understanding in discussions. Meanwhile, different technical backgrounds result indirectly in team members lacking in consensuses. Take case 1 for example. Some members don't care much about the working schedule. Different perceptions on the working schedule may result in conflicts in multidisciplinary coordination. Besides, when multidisciplinary team members face a totally unfamiliar strange field, they are not sure about what they can do and what assignments to undertake.

Another problem with specialty is team composition. As shown in case 3 , when staffing was disproportionate, a specific specialty might take up a very large share, impacting indirectly on the discussions and decision making in respect of other specialties. In this case, the team leaned to that specialty.

\section{Job Assignment and Role Positioning}

Case 2 and case 3 dealt separately with two absolutely different leadership modes. In case 2 where the team had a longtime leader, there might be an unbalance in task allocation and decision making. Besides, too assertive a leader might hurt the creativity and development of a team. In case 3 where there was a lack in consistent leadership or where leaders differ at different stages, the team faced coordination and task allocation problems that impacted adversely on teamwork.

In addition to leadership-related task allocation, unclear role division may cause problematic role positioning, equivocal self-awareness and task allocation-based conflicts.

\section{Relationship}

The relationship problem arises out of the relationship among people. The team members are normally unfamiliar with each other at the initial stage, yet as team interaction and development deepen, they become more familiar. However, because of a diverse nature, a multidisciplinary team is likely to develop common goal problems which, if not addressed appropriately, are likely to result in more divides in opinion among the members with the growth of the team. More seriously, the members may disagree on issues which aggravate lack of mutual trust and individual coordination. All these are symbolic of the negative impact on team development.

\section{Communication}

The study defined two major communication problems, i.e., conflicts of ideas and opinions, and communication ability inadequacy. The study held that while conflicts of ideas and opinions are unavoidable in a multidisciplinary team and can, to some degree, inspire team creativity, unreasonable attitudes and uncompromising obstinacy can escalate into serious conflicts and hinder team cohesion and development.

\section{Attitude}

The study found that the attitude problem concerns either stubborn persistence in one's specialty or reluctance to be joined by members of other specialties. Both cases arise out of technical background difference. In other cases, a majority of participants in discussions do not respond or give their tacit consent. This inactivity leads to the failure of the members to exchange ideas and develop creativity. The 
team may be bogged down in darkness without feedback and developments. Another attitude problem is with case 4, where some members assuming instructor roles "deigned" to work with other members. Unlike tacit consent and no response, the attitude makes communication difficult and may, to some extent, impact adversely team cohesion.

\section{Efficiency}

The study reduced all working progress problems down to low efficiency. In case 3, any suggestion put forward by anybody was discussed, so it was impossible to filter out inapplicable suggestions with speed. This resulted in low team efficiency. Besides, some multidisciplinary teams often fail to arrive at reasonable solutions, leaving the problems unattended with virtually no progress.

\section{External Factors}

Apart from internal problems, a multidisciplinary team also faces a lot of external factors, e.g., funding insufficiency, time insufficiency, geographical distance, client dissatisfaction and other problems out of the control of the team. In case 4 , the motivation of some members didn't comply with the team goals. In this study, the team members were "forced" to hold together under the irresistible influence of factors. Besides, grouping of many current multidisciplinary programs and workshops is requested by the instructors or conducted in the form of lots draw, that is to say, the instructors intervenes in the programs directly or make allocations randomly. The arrangement is uncontrollable per se, so it's deemed as an external factor.

\section{CONCLUSION}

Through above methods, this study found that conflicts encountered by multidisciplinary collaboration can be classified into nine categories: professional background, team composition, job assignment, role positioning, relationship, communication, attitude, efficiency and external factors, as shown in the Table 8 below.

TABLE 8. The problem induction of all case

\begin{tabular}{|c|c|c|c|c|c|c|}
\hline Problem/Case & Case 1 & Case 2 & Case 3 & Case 4 & Case 5 & Total \\
\hline Professional background & & & & & & 4 \\
\hline Team composition & & & & & & 2 \\
\hline Job assignment & & & & & & 2 \\
\hline Role positioning & & & & & & 2 \\
\hline Relationship & & & & & & 4 \\
\hline Communication & & & & & & 3 \\
\hline Attitude & & & & & & 3 \\
\hline Efficiency & & & & & & 1 \\
\hline External factors & & & & & & 2 \\
\hline Total & 4 & 5 & 6 & 5 & 3 & \\
\hline
\end{tabular}

It can be seen from the above table that each case had got different conflicts. There are four types of problems in case 1 , professional background problem, job assignment problem, attitude problem and external problem. The composition of groups of different fields is kind of complicated against the Field Composition Table, and three multidisciplinary teams of which are in contact with the clients, which result in external factor related problems; in case 2, there are five kinds of problems respectively with regard to professional background, team composition, relationship, communication and attitude. As shown from its Field Composition Table, these are common problems occurred during the collaboration between design teams and management teams; case 3 is found with six problems related to professional background, team composition, role positioning, relationship, communication, attitude and efficiency, simi- larly, it's team composition is relatively complicated as well, but compared with case one, there is no external factor related conflict as the intervention of project manager differs from that of the client; in case 4, five types of problems, namely specialty problem, role positioning problem, relationship problem, attitude problem, and external factors are witnessed, which may occur in the multidisciplinary collaboration between engineering teams and management teams according to the Table 7; case 5 is found with three problems related to job assignment, relationship and communication, which may come about in cross-field collaboration between designing, engineering and management teams.

In terms of the frequency of occurrence, professional background problems and relationship problems were the most frequent in the five cases of cross-field teamwork, both were 
four out of five; the next one is communication and attitude problems, both were three out of five; and then team composition, job assignment, role positioning and external factors featured two out of five; the efficiency problem was found only once.

TABLE 9. The problem induction of all case

\begin{tabular}{|c|c|c|c|c|c|}
\hline \multirow[t]{2}{*}{ Number } & \multicolumn{4}{|c|}{ Field of the Team Composition } & \multirow[t]{2}{*}{ Number of Groups } \\
\hline & Design & Engineering & Management & Operator/Other & \\
\hline \multirow[t]{4}{*}{ Case 1} & & & & & 1 \\
\hline & & & & & 5 \\
\hline & & & & (Operator) & 1 \\
\hline & & & & (Operator) & 2 \\
\hline Case 2 & & & & & 12 \\
\hline \multirow[t]{3}{*}{ Case 3} & & & & & 1 \\
\hline & & & & & 2 \\
\hline & & & & (project Manager) & 1 \\
\hline Case 4 & & & & & 1 \\
\hline Case 5 & & & & & 4 \\
\hline
\end{tabular}

\section{LIMITATIONS AND RECOMMENDATIONS}

Although interdisciplinary team conflict can be classified as nine problems, the complexity of the sample teams' composition (see the above Table 9) in this study makes it insufficient to explain the reasons for the cross-cutting teamwork issues in various fields when working with other fields. Therefore, it is suggested that researchers can conduct research on specific fields to identify the influencing factors of cross-field teamwork in specific fields.

\section{REFERENCES}

Brown, S. L., \& Eisenhardt, K. M. (1995). Product development: Past research, present findings, and future directions. Academy of Management Review, 20(2), 343-378. doi:https://doi.org/10.2307/258850

Chen, W.-J. (2012). Competition learning through cross-disciplinary collaboration in the entrepreneur competition (Unpublished master dissertation). Far East University, Tainan City, Taiwan.

Coser, L. A. (1998). The functions of social conflict (Vol. 9). New York, NY: Routledge.

Cross, N., \& Cross, A. C. (1995). Observations of teamwork and social processes in design. Design Studies, 16(2), 143-170. doi:https://doi.org/10.1016/0142-694x(94)00007-z

Denton, H. G. (1997). Multidisciplinary team-based project work: Planning factors. Design Studies, 18(2), 155-170. doi: https://doi.org/10.1016/s0142-694x(97)85458-0

Guetzkow, H., \& Gyr, J. (1954). An analysis of conflict in decision-making groups. Human Relations, 7(3), 367-382. doi: https://doi.org/10.1177/001872675400700307

Guzzo, R. A., Yost, P. R., Campbell, R. J., \& Shea, G. P. (1993). Potency in groups: Articulating a construct. British Journal of Social Psychology, 32(1), 87-106. doi:https://doi.org/10.1111/j.2044-8309.1993.tb00987.x

Hou, M.-C. (2007). A study on cross-curricular program of universities in Taiwan (Unpublished master dissertation). National Chiao Tung University, Hsinchu City, Taiwan.

Huang, K.-P. (2009). The concept thinking context of interdisciplinary design team - a case study of joining members in sociology department. Unpublished doctoral dissertation, Tokai University, Tokyo, Japan.

Jehn, K. A. (1997). A qualitative analysis of conflict types and dimensions in organizational groups. Administrative Science Quarterly, 42(3), 530-557. doi:https://doi.org/10.2307/2393737

Ke, C.-W. (2008). Exploring multidisciplinary teamwork design process for cross-disciplinary learning. Unpublished doctoral dissertation, Institute of Creative Industry Design, Tainan, Taiwan.

Kunhui, H., \& Derui, Z. (2000). Conflict. Retrieved from https://bit.1y/2FsKwjb

Lai, Y.-M. (2010). A study of the relationships between leader personality, team learning, and team performance - evidence from cross-functional design courses (Master's thesis). National Taiwan University of Science and Technology, Taipei, Taiwan. 
Lan, T.-C. (2012). Exploring the integrating process of the cross-field open innovation team: A case study of promoting program for cross-field creative scenario value-adding of national science council (Unpublished master dissertation). National Cheng Kung University, Tainan City, Taiwan.

Lay, W.-I. (2012). The cross-disciplinary team design model of cultural products (Master's thesis). National Success University, Tainan, Taiwan.

$\mathrm{Li}, \mathrm{R} .-\mathrm{S}$. (2017). hree things to consider before inter-disciplinary talent cultivation. Retrieved from https: //bit. ly/2QtiVoi

Lin, C.-Y. (2011). The case study of establishing interdisciplinary R\&D team by academy cooperation between a university and Romp enterprise co. (Master's thesis). Chaoyang University of Science and Technology, Taichung, Taiwan.

Lin, Y.-C. (2010). Exploring the influence of scenario approach on multidisciplinary collaboration design - an case study of user-oriented innovative design course (Master dissertation). National Taiwan University of Science and Technology, Taipei, Taiwan.

Liu, H., \& Dong, X. (2016). Influence of social relations on knowledge conflicts-an empirical study from Chinese universities. Journal of Administrative and Business Studies, 2(1), 8-18. doi:https://doi.org/10.20474/jabs-2.1.2

Liu, P.-L., Yue, X.-P., Shen, H.-J., Wang, A.-B., Xiao, Z.-J., Lin, X.-Q., ... Li, S.-G. (2006). Promotion and results of the crossdisciplinary science and technology education platform program. Retrieved from https://bit.1y/3907b7G

Ministry of Education. (2013). Ministry of education talent cultivation. Retrieved from https://bit. Iy/2ZWPzSx

Nissa, N. U., Jhatial, A. A., Nawaz, M., \& Halepota, J. A. (2018). Conflict management styles (dominating and compromising) of academic administration and its impact on faculty job satisfaction and turnover intention. International Journal of Business and Administrative Studies, 4(5), 187-196. doi:https://dx.doi.org/10.20469/ijbas.4.10001-5

$\mathrm{Ou}, \mathrm{C}$. (2009). An empirical study of how academic motivation and social ability influence on learning outcome in crossdisciplinary collaborative learning (Master's thesis). National Central University, Taoyuan City, Taiwan.

Parry, M. E., \& Song, X. M. (1993). Determinants of R\&D-marketing integration in high-tech Japanese firms. Journal of Product Innovation Management, 10(1), 4-22. doi:https://doi.org/10.1111/1540-5885.1010004

Pondy, L. R. (1967). Organizational conflict: Concepts and models. Administrative Science Quarterly, 13(3), 296-320. doi: https://doi.org/10.1002/job.4030130304

Raditya, W. (2018). Influnce of role conflict, authorities of jobs in employee work satisfaction. International Journal of Business and Economic Affairs, 3(4), 160-170. doi:https://doi.org/10.24088/ijbea-2018-34003

Robbins, S. P. (1996). Organizational behavior. Englewood Cliffs, NJ: Prentice Hall International Ltd.

Ruan, L.-Y., \& et al. (2012). Design research method. Taipei, Taiwan: Quanhua Technology Book Co., Ltd.

Shaw, J. D., Duffy, M. K., \& Stark, E. M. (2000). Interdependence and preference for group work: Main and congruence effects on the satisfaction and performance of group members. Journal of Management, 26(2), 259-279. doi:https://doi.org/ $10.1177 / 014920630002600205$

Shih, C.-Y. (2017). A study of integrating mechanism for the cross-field team between performing arts and technology (Master's thesis). National Taiwan Normal University, Taipei, Taiwan.

Shonk, J. H. (1982). Working in teams: A practical manual for improving work groups. New York, NY: Amacom.

Tang, H.-H., \& Lin, Y.-C. (2011). The influence and problems of scenario design approach on multi-disciplinary collaboration design. Journal of Design, 16(3), 21-41.

Tsao, C.-W. (2014). The study of using animation to convey the business model and guiding the multidisciplinary design team innovation activities. Unpublished doctoral dissertation, National Yunlin University of Science and Technology, Douliu, Taiwan.

Wheelwright, S. C., \& Clark, K. B. (1992). Revolutionizing product development: Quantum leaps in speed, efficiency, and quality. New York, NY: Simon and Schuster.

$\mathrm{Wu}, \mathrm{C}$-H. (2010). The research of applying electronic learning portfolio in cross-disciplinary collaborative learning (Master's thesis). National Taipei University of Education, Taipei, Taiwan.

Wu, K.-Y. (2017). Team learning in open innovation teams: The case of the most promoting program for cross-field creative scenario value-adding (Unpublished thesis). National Success University, Tainan, Taiwan.

Yeh, Y.-L. (2009). Exploring the process of interdisciplinary communication-a case study of design and marketing interdisciplinary team (Unpublished master dissertation). Chung Yuan Christian University, Taoyuan County, Taiwan.

Zhao, X.-H. (2014). First-class companies must have t-type talents. Retrieved from https://bit.1y/2sXjqho 